\title{
Antibody-Based Ticagrelor Reversal Agent in Healthy Volunteers.
}

\author{
Deepak L. Bhatt \\ Harvard Medical School \\ Charles V. Pollack \\ Thomas Jefferson University \\ Jeffrey I. Weitz \\ McMaster University \\ Lisa K. Jennings \\ University of Tennessee Health Science Center \\ Sherry Xu \\ PhaseBio Pharmaceuticals \\ Follow this and additional works at: https://jdc.jefferson.edu/emfp \\ see rextof the fordiolitionapauthors \\ Let us know how access to this document benefits you
}

\section{Recommended Citation}

Bhatt, Deepak L.; Pollack, Charles V.; Weitz, Jeffrey I.; Jennings, Lisa K.; Xu, Sherry; Arnold, Susan E.; Umstead, Bret R.; Mays, Michael C.; and Lee, John S., "Antibody-Based Ticagrelor Reversal Agent in Healthy Volunteers." (2019). Department of Emergency Medicine Faculty Papers. Paper 88.

https://jdc.jefferson.edu/emfp/88

This Article is brought to you for free and open access by the Jefferson Digital Commons. The Jefferson Digital Commons is a service of Thomas Jefferson University's Center for Teaching and Learning (CTL). The Commons is a showcase for Jefferson books and journals, peer-reviewed scholarly publications, unique historical collections from the University archives, and teaching tools. The Jefferson Digital Commons allows researchers and interested readers anywhere in the world to learn about and keep up to date with Jefferson scholarship. This article has been accepted for inclusion in Department of Emergency Medicine Faculty Papers by an authorized administrator of the Jefferson Digital Commons. For more information, please contact: JeffersonDigitalCommons@jefferson.edu. 
Authors

Deepak L. Bhatt, Charles V. Pollack, Jeffrey I. Weitz, Lisa K. Jennings, Sherry Xu, Susan E. Arnold, Bret R. Umstead, Michael C. Mays, and John S. Lee 
ORIGINAL ARTICLE

\section{Antibody-Based Ticagrelor Reversal Agent in Healthy Volunteers}

\author{
Deepak L. Bhatt, M.D., M.P.H., Charles V. Pollack, M.D., Jeffrey I. Weitz, M.D., \\ Lisa K. Jennings, Ph.D., Sherry Xu, Ph.D., Susan E. Arnold, Ph.D., \\ Bret R. Umstead, M.S., Michael C. Mays, B.S., and John S. Lee, M.D., Ph.D.
}

ABSTRACT

BACKGROUND

Ticagrelor is an oral P2 $\mathrm{Y}_{12}$ inhibitor that is used with aspirin to reduce the risk of ischemic events among patients with acute coronary syndromes or previous myocardial infarction. Spontaneous major bleeding and bleeding associated with urgent invasive procedures are concerns with ticagrelor, as with other antiplatelet drugs. The antiplatelet effects of ticagrelor cannot be reversed with platelet transfusion. A rapid-acting reversal agent would be useful.

\section{METHODS}

In this randomized, double-blind, placebo-controlled, phase 1 trial, we evaluated intravenous PB2452, a monoclonal antibody fragment that binds ticagrelor with high affinity, as a ticagrelor reversal agent. We assessed platelet function in healthy volunteers before and after 48 hours of ticagrelor pretreatment and again after the administration of PB2452 or placebo. Platelet function was assessed with the use of light transmission aggregometry, a point-of-care $\mathrm{P}_{2} \mathrm{Y}_{12}$ platelet-reactivity test, and a vasodilator-stimulated phosphoprotein assay.

\section{RESULTS}

Of the 64 volunteers who underwent randomization, 48 were assigned to receive PB2452 and 16 to receive placebo. After 48 hours of ticagrelor pretreatment, platelet aggregation was suppressed by approximately $80 \%$. PB2452 administered as an initial intravenous bolus followed by a prolonged infusion $(8,12$, or 16 hours) was associated with a significantly greater increase in platelet function than placebo, as measured by multiple assays. Ticagrelor reversal occurred within 5 minutes after the initiation of $\mathrm{PB} 2452$ and was sustained for more than 20 hours $(\mathrm{P}<0.001$ after Bonferroni adjustment across all time points for all assays). There was no evidence of a rebound in platelet activity after drug cessation. Adverse events related to the trial drug were limited mainly to issues involving the infusion site.

CONCLUSIONS

In healthy volunteers, the administration of PB2452, a specific reversal agent for ticagrelor, provided immediate and sustained reversal of the antiplatelet effects of ticagrelor, as measured by multiple assays. (Funded by PhaseBio Pharmaceuticals; ClinicalTrials.gov number, NCT03492385.)
From the Brigham and Women's Hospital Heart and Vascular Center and Harvard Medical School, Boston (D.L.B.); the Department of Emergency Medicine, Thomas Jefferson University, Philadelphia (C.V.P.); McMaster University and the Thrombosis and Atherosclerosis Research Institute, Hamilton, ON, Canada (J.I.W.); CirQuest Labs and the University of Tennessee Health Science Center, Memphis (L.K.J.); and PhaseBio Pharmaceuticals, Malvern, PA (S.X., S.E.A., B.R.U., M.C.M., J.S.L.). Address reprint requests to Dr. Bhatt at the Brigham and Women's Hospital Heart and Vascular Center, Harvard Medical School, 75 Francis St., Boston, MA 02115, or at dlbhattmd@post harvard.edu.

This article was published on March 17, 2019, at NEJM.org.

N Engl J Med 2019;380:1825-33. DOI: 10.1056/NEJMoa1901778 Copyright (๑) 2019 Massachusetts Medical Society. 
NTIPLATELET THERAPY IS AN ESSENTIAL part of secondary prevention of cardiovascular events. ${ }^{1,2}$ In particular, dual antiplatelet therapy - the combination of aspirin with an oral $\mathrm{P}_{2} \mathrm{Y}_{12}$ receptor antagonist - is the predominant approach in patients with acute coronary syndromes, coronary-artery stenting, or previous myocardial infarction. ${ }^{3-19}$ The three oral $\mathrm{P}^{2} \mathrm{Y}_{12}$ receptor antagonists that are in use are clopidogrel, prasugrel, and ticagrelor.

A limitation of all three oral $\mathrm{P}_{2} \mathrm{Y}_{12}$ receptor antagonists is the increased bleeding risk, which persists for several days after drug cessation. ${ }^{20-23}$ Establishment of hemostasis can be challenging in patients with major bleeding, such as intracranial or gastrointestinal hemorrhage. ${ }^{24,25}$ In addition, urgent invasive procedures, especially emergency procedures, are associated with an increased risk of periprocedural bleeding. If an emergency procedure is indicated, the surgeon or proceduralist must proceed while accepting the increased bleeding risk, often after empirically providing platelet transfusions, despite the ineffectiveness of such transfusions in reversing the antiplatelet effects of $\mathrm{P}_{2} \mathrm{Y}_{12}$ inhibitors. If an urgent procedure is indicated, the proceduralist must either proceed while anticipating the increased bleeding risk or postpone the procedure for several days while accepting the risks associated with delaying a clinically indicated procedure. American College of Cardiology Foundation-American Heart Association, European Society of Cardiology, and other society guidelines recommend cessation of oral $\mathrm{P} 2 \mathrm{Y}_{12}$ receptor antagonists at least 3 to 7 days before surgery. ${ }^{26,27}$

Currently, no reversal agents for $\mathrm{P}_{2} \mathrm{Y}_{12}$ receptor antagonists are known. Unlike the other $\mathrm{P}_{2} \mathrm{Y}_{12}$ receptor antagonists, ticagrelor is a reversible inhibitor, which makes the development of a specific reversal agent for ticagrelor feasible. PB2452 (formerly MEDI2452) is a neutralizing monoclonal antibody fragment that binds ticagrelor and its major active circulating metabolite with high affinity. ${ }^{28}$ We hypothesized that PB2452 could be used to reverse rapidly the antiplatelet effects of ticagrelor, thereby reducing the risk or severity of bleeding.

METHODS

TRIAL DESIGN AND OVERSIGHT

We conducted a single-center, randomized, doubleblind, placebo-controlled, single-ascending-dose, phase 1 trial to evaluate the safety, efficacy, and pharmacokinetic profiles of PB2452 in healthy volunteers 18 to 50 years of age who were pretreated with ticagrelor. As shown in Table S1 in the Supplementary Appendix (available with the full text of this article at NEJM.org), 10 sequential dose cohorts were evaluated. Volunteers in all cohorts were randomly assigned, in a 3:1 ratio, to receive PB2452 or placebo.

Cohorts 1, 2, and 3 each consisted of four volunteers who were randomly assigned to receive a 30-minute infusion of PB2452 at a dose of $0.1 \mathrm{~g}$, $0.3 \mathrm{~g}$, and $1.0 \mathrm{~g}$, respectively, or placebo, in the absence of ticagrelor pretreatment, to assess the initial safety of PB2452. Volunteers in cohorts 4 through 10 were pretreated with a 180-mg loading dose of oral ticagrelor at 7 a.m. on day -2 , and then with a 90-mg dose every 12 hours starting at 7 p.m. on day -2 , for a total of five doses and 48 hours of pretreatment before the evaluation of PB2452. Cohorts 4, 5, and 6 each consisted of eight volunteers who were assigned to receive a 30 -minute infusion of PB2452 at a dose of $1.0 \mathrm{~g}, 3.0 \mathrm{~g}$, and $9.0 \mathrm{~g}$, respectively, or placebo after ticagrelor pretreatment. Cohorts 7 through 10 consisted of volunteers who were assigned to receive an 18.0-g fixed dose of PB2452 according to one of four infusion regimens or placebo after ticagrelor pretreatment. In cohorts 7 through 10, PB2452 was initiated 2 hours after the administration of the last dose of ticagrelor pretreatment to coincide with the peak concentration of ticagrelor. ${ }^{29}$

Volunteers were enrolled at Pharmaceutical Product Development, a contract clinical research organization. PhaseBio Pharmaceuticals sponsored the trial. A steering committee, which consisted of academic physicians and a representative from PhaseBio Pharmaceuticals, developed the protocol (available at NEJM.org) and was responsible for the conduct and oversight of the trial, as well as the interpretation of the data. Pharmaceutical Product Development was responsible for the collection and handling of the data. The protocol was approved by the Food and Drug Administration and a central institutional review board. All data analyses were performed by PhaseBio Pharmaceuticals. The first author wrote the first draft of the manuscript, and all the authors participated in revisions of subsequent drafts. No one who is not an author contributed to writing the manuscript. The authors vouch for the completeness and accuracy of the data and analyses and for the fidelity of the trial to the protocol. 


\section{ELIGIBILITY}

Eligible volunteers were healthy men and women 18 to 50 years of age, with a weight of 50 to $120 \mathrm{~kg}$ and a body-mass index (the weight in kilograms divided by the square of the height in meters) of 18 to 35. Volunteers who had any contraindication to ticagrelor, a medical history suggestive of an increased bleeding risk, or an estimated glomerular filtration rate of less than $60 \mathrm{ml}$ per minute per $1.73 \mathrm{~m}^{2}$ of body-surface area were excluded. Written informed consent was obtained from all volunteers. No effort was made to balance the groups on the basis of age, race or ethnic group, or sex.

\section{OUTCOMES}

The primary efficacy outcome was reversal of the antiplatelet effects of ticagrelor as assessed by analysis of platelet aggregation with the use of light transmission aggregometry at multiple time points before and after the administration of PB2452 or placebo in volunteers who were pretreated with ticagrelor. Secondary efficacy outcomes were ticagrelor reversal as assessed with the use of a point-of-care $\mathrm{P}_{2} \mathrm{Y}_{12}$ platelet-reactivity test known as the VerifyNow P2Y12 assay (Accriva) and a vasodilator-stimulated phosphoprotein (VASP) phosphorylation immunoassay known as the modified CY-QUANT VASP P2Y12 assay (BioCytex). Details regarding these assays and the interpretation of their results are provided in the Methods section of the Supplementary Appendix.

The primary safety outcome was the frequency and severity of adverse events that occurred after the initiation of PB2452 or placebo. Association of adverse events with PB2452, both in volunteers who received ticagrelor pretreatment and in those who did not, was determined by the investigator. Clinical laboratory test results, vital signs, results of 12-lead electrocardiography and continuous telemetry, and findings on physical examination were also obtained at multiple time points from screening to the end of the 28-day safety followup period. The immunogenicity of PB2452 was assessed before the administration of PB2452, as well as 7 days and 28 days afterward. Other secondary outcomes included the pharmacokinetic profiles of PB2452 and ticagrelor.

\section{STATISTICAL ANALYSIS}

The sample of 64 volunteers was an ad hoc decision that was based on the requirement that 4 or 8 volunteers be randomly assigned, in a 3:1 ra- tio, to receive either PB2452 or placebo in each dose cohort to explore adequately the safety, efficacy, and pharmacokinetic profiles of PB2452 in healthy volunteers. Reversal of the antiplatelet effects of ticagrelor was evaluated by comparing the platelet aggregation after treatment, which was expressed as a percentage of the platelet aggregation at baseline, between PB2452 and placebo with the use of the Wilcoxon rank-sum test. For efficacy data, baseline was defined as the time point immediately before the administration of ticagrelor. The Bonferroni method was used to adjust for multiple comparisons. Correlation of results between platelet-function tests was evaluated with the use of Pearson's correlation coefficient and Spearman's rank-correlation coefficient.

Mean data from volunteers who received placebo were pooled across cohorts for all analyses. Results for categorical variables are summarized with frequencies and percentages, and results for continuous variables are presented with the number of volunteers with nonmissing data, as well as means with standard deviations and medians with ranges. Descriptive statistics are presented for each cohort and for pooled placebo and PB2452 data. Platelet aggregation results were compared between each PB2452 cohort and pooled placebo data (with data for cohorts 4, 5, and 6 and data for cohorts 7 through 10 pooled separately). All analyses were performed with SAS software, version 9.4 (SAS Institute). Details regarding all statistical analyses are provided in the protocol, which includes the statistical analysis plan.

\section{RESULTS}

\section{TRIAL POPULATION}

From April 3, 2018, to August 23, 2018, a total of 64 volunteers underwent randomization, of whom 48 were assigned to receive PB2452 and 16 to receive placebo. Of the 48 volunteers who received PB2452, 21 received the highest dose (18 g) and 39 received ticagrelor pretreatment. Details regarding the final trial design and regarding enrollment, randomization, and follow-up are shown in Table S1 and Figure S1, respectively, in the Supplementary Appendix. Characteristics of the volunteers at baseline are shown in Table 1.

\section{SAFETY}

A total of 30 adverse events that occurred after initiation of PB2452 or placebo were reported by 19 of the 64 volunteers (30\%). Of the 48 volunteers 


\begin{tabular}{|c|c|c|}
\hline Characteristic & $\begin{array}{l}\text { Placebo } \\
(\mathrm{N}=16)\end{array}$ & $\begin{array}{l}\text { PB2452 } \\
(N=48)\end{array}$ \\
\hline Age $-y r$ & $34.0 \pm 8.3$ & $30.5 \pm 8.8$ \\
\hline \multicolumn{3}{|l|}{ Sex-no. (\%) } \\
\hline Male & $11(69)$ & $23(48)$ \\
\hline Female & $5(31)$ & $25(52)$ \\
\hline Weight - kg & $86.2 \pm 13.5$ & $78.2 \pm 14.8$ \\
\hline Height $-\mathrm{cm}$ & $173.3 \pm 6.4$ & $167.8 \pm 10.2$ \\
\hline Body-mass index $†$ & $28.6 \pm 3.3$ & $27.7 \pm 4.1$ \\
\hline \multicolumn{3}{|l|}{ Race or ethnic group - no. $(\%) \ddagger$} \\
\hline White & $7(44)$ & $27(56)$ \\
\hline Black & $8(50)$ & $18(38)$ \\
\hline Asian & 0 & $1(2)$ \\
\hline American Indian or Alaska Native & $1(6)$ & 0 \\
\hline Native Hawaiian or Pacific Islander & 0 & $1(2)$ \\
\hline Multiple & 0 & $1(2)$ \\
\hline \multicolumn{3}{|l|}{ Hispanic ethnic group - no. (\%) $\ddagger$} \\
\hline Hispanic & $6(38)$ & $22(46)$ \\
\hline Not Hispanic & $10(62)$ & $26(54)$ \\
\hline Platelet count per $\mathrm{mm}^{3}$ & $239,000 \pm 52,100$ & $253,000 \pm 46,800$ \\
\hline $\begin{array}{c}\text { Platelet aggregation on light transmis- } \\
\text { sion aggregometry — \%』 }\end{array}$ & $82.1 \pm 7.5$ & $82.9 \pm 7.5$ \\
\hline $\begin{array}{l}\text { Platelet reactivity units on point-of-care } \\
\qquad \text { P2Y }_{12} \text { platelet-reactivity test } \emptyset\end{array}$ & $226.4 \pm 39.9$ & $237.7 \pm 36.8$ \\
\hline Platelet reactivity index on VASP assay $\|$ & $89.8 \pm 4.2$ & $90.2 \pm 3.6$ \\
\hline
\end{tabular}

* Plus-minus values are means \pm SD. In general, the baseline value was defined as the last nonmissing measurement obtained before randomization. There were no significant differences between the groups with regard to baseline characteristics.

$\uparrow$ The body-mass index is the weight in kilograms divided by the square of the height in meters.

$\checkmark$ Race or ethnic group was reported by the volunteer.

$\int$ On light transmission aggregometry, the normal range for platelet aggregation is 72 to $94 \%$ (CirQuest Labs in-house validation).

9 On the point-of-care $\mathrm{P}_{2} \mathrm{Y}_{12}$ platelet-reactivity test (VerifyNow P2Y12 assay), the normal range for platelet reactivity units is 180 to 380 (Accriva package insert).

$\|$ On the vasodilator-stimulated phosphoprotein (VASP) assay (modified CY-QUANT VASP P2Y12), the normal range for the platelet reactivity index is 89 to $99 \%$ (BioCytex package insert).

who received PB2452, 17 (35\%) reported 27 adverse events; of the 16 volunteers who received placebo, 2 (12\%) reported 3 adverse events (Table 2). There were no dose-limiting toxic effects or infusionrelated reactions. There were no deaths or adverse events that led to discontinuation of the trial drug or hospitalization. One volunteer had 2 serious adverse events (alcohol poisoning and acute respiratory failure) 4 days after discharge from the clinical site. Except for 2 volunteers, in cohorts 1 and 3, all volunteers with adverse events had received ticagrelor pretreatment. Changes in mean clinical laboratory test results, vital signs, and electrocardiographic results were similar across cohorts among volunteers who received different doses or regimens of PB2452 and were similar among those who received PB2452 and those who received placebo.

Of the 48 volunteers who received PB2452, 21 (44\%) had detectable antidrug antibodies in blood obtained 7 days, 28 days, or both after exposure; 15 (31\%) had been positive before they received PB2452 and 6 (12\%) became positive after they received PB2452, albeit with low titers of 40 (in 5 volunteers) and 160 (in 1 volunteer). Of the 16 volunteers who received placebo, 3 (19\%) were positive for antidrug antibodies, with $2(12 \%)$ having preexisting antibodies. All antibody titers were less than 1280, and the presence of these antibodies had no observed effect on the safety or efficacy of PB2452.

\section{TICAGRELOR REVERSAL}

Ticagrelor reversal was assessed in cohorts 4 through 10 by analysis of platelet aggregation. Volunteers in these cohorts were pretreated with ticagrelor for 48 hours before they received PB2452 or placebo. Among volunteers who received placebo, platelet aggregation was suppressed by 80 to $85 \%$ after 48 hours of ticagrelor pretreatment and remained suppressed for an additional 24 hours after ticagrelor cessation. Platelet aggregation gradually returned closer to normal between 24 and 48 hours after the initiation of placebo (Fig. 1). Volunteers in cohorts 5 and 6 who received a 30-minute infusion of PB2452 at a dose of $3.0 \mathrm{~g}$ and $9.0 \mathrm{~g}$, respectively, had a significantly greater increase in platelet aggregation than those who received placebo. Maximal ticagrelor reversal occurred at 30 minutes, immediately after completion of the 30-minute infusion. The duration of reversal was dose-dependent and lasted 1 to 2 hours (Fig. 1A).

To attain more rapid and sustained ticagrelor reversal, the total dose of PB2452 was increased to $18 \mathrm{~g}$ in cohorts 7 through 10 to accommodate the administration of an initial bolus and longer infusions of 8,12 , and 16 hours. In cohort 7, PB2452 was administered as a 3.0-g bolus followed by an 8-hour infusion. Although use of this regimen significantly extended the duration of reversal to 
approximately 12 hours, the onset of reversal was delayed by approximately 2 hours (Fig. 1B). In cohorts 8, 9, and 10, PB2452 was administered as a 6.0 -g bolus followed by a 12 -hour or 16 -hour infusion. With the larger bolus, reversal occurred within 5 minutes after initiation of the infusion and was sustained for 16 to 24 hours (Fig. 1B). Overall, in cohorts 7 through 10, in which the PB2452 regimen was adjusted to include an initial bolus for rapid reversal and a prolonged infusion for sustained reversal, volunteers who received PB2452 (pooled) had a significantly greater increase in platelet aggregation than those who received placebo (pooled) across all time points between 5 minutes and 20 hours $(\mathrm{P}<0.001$ after Bonferroni adjustment).

The significant immediate and sustained ticagrelor reversal that was detected with light transmission aggregometry in the primary efficacy analysis was confirmed with the point-of-care $\mathrm{P}_{12}$ platelet-reactivity test and VASP assay (Fig. S2A and S2B in the Supplementary Appendix). Correlation analyses of results on the three plateletfunction tests revealed significant correlation for all comparisons, with $r$ values of 0.91 or higher and 0.81 or higher for the Pearson's and Spearman's analyses, respectively $(\mathrm{P}<0.001$ for all comparisons) (Fig. S3 in the Supplementary Appendix).

To assess the extent to which normal platelet function was restored, in cohorts 9 and 10 (pooled), platelet function after the initiation of PB2452 was compared with platelet function at baseline (before the administration of ticagrelor) with the use of all three assays. On light transmission aggregometry, the mean platelet aggregation was restored to a normal level ( $\geq 80 \%$ of the baseline value) at all time points up to 20 hours (Fig. 2A). On the point-of-care $\mathrm{P}_{2} \mathrm{Y}_{12}$ platelet-reactivity test, the mean platelet reactivity reflected rapid and sustained normalization of platelet function, with a level of platelet reactivity units of at least 180 , for 24 hours (Fig. 2B). On assessment of $\mathrm{P}_{12}$ receptor signaling with the VASP assay, the platelet reactivity index was restored to nearly $100 \%$ of the baseline value within 5 minutes and remained at that level for 20 to 24 hours (Fig. 2C).

To determine whether acute ticagrelor reversal causes a potentially prothrombotic rebound effect in platelet reactivity, platelet aggregation was assessed in response to a low concentration of adenosine diphosphate ( $5 \mu \mathrm{M}$, as compared with the usual $20 \mu \mathrm{M}$ ). In addition, platelet aggregation was

\begin{tabular}{|c|c|c|}
\hline Variable & $\begin{array}{l}\text { Placebo } \\
(N=16)\end{array}$ & $\begin{array}{l}\text { PB2452 } \\
\text { (N=48) }\end{array}$ \\
\hline Any event - no. & 3 & 27 \\
\hline Volunteers with event - no. $(\%) \dagger$ & $2(12)$ & $17(35)$ \\
\hline Bruising at infusion site & 0 & $4(8)$ \\
\hline Reaction at medical device site & 0 & $3(6)$ \\
\hline Bruising at vessel puncture site & 0 & $2(4)$ \\
\hline Extravasation at infusion site & 0 & $2(4)$ \\
\hline Abdominal pain & 0 & $1(2)$ \\
\hline Acute respiratory failure & 0 & $1(2)$ \\
\hline Alcohol poisoning & 0 & $1(2)$ \\
\hline Aspiration pneumonia & 0 & $1(2)$ \\
\hline Blood in urine & 0 & $1(2)$ \\
\hline Conjunctivitis & 0 & $1(2)$ \\
\hline Contusion & $1(6)$ & 0 \\
\hline Dizziness & 0 & $1(2)$ \\
\hline Eyelid irritation & $1(6)$ & 0 \\
\hline Gastroenteritis & 0 & $1(2)$ \\
\hline Hematuria & 0 & $1(2)$ \\
\hline Musculoskeletal chest pain & $1(6)$ & 0 \\
\hline Nasopharyngitis & 0 & $1(2)$ \\
\hline Oropharyngeal pain & 0 & $1(2)$ \\
\hline Reaction at infusion site & 0 & $1(2)$ \\
\hline Skin abrasion & 0 & $1(2)$ \\
\hline Streptococcal pharyngitis & 0 & $1(2)$ \\
\hline Upper limb fracture & 0 & $1(2)$ \\
\hline
\end{tabular}

* Shown are adverse events that occurred after initiation of PB2452 or placebo. The terms are based on codes from the Medical Dictionary for Regulatory Activities, version 21.0.

$\uparrow$ For each entry, a volunteer is counted once if he or she reported one or more events.

assessed in response to other agonists, including arachidonic acid and thrombin receptor-activating peptide. As expected, the response was lower with $5 \mu \mathrm{M}$ of adenosine diphosphate than with $20 \mu \mathrm{M}$ (Fig. S4A and S4B in the Supplementary Appendix), and the responses to arachidonic acid and thrombin receptor-activating peptide after reversal were similar to the responses at baseline (before the administration of ticagrelor) (Fig. S4C and S4D in the Supplementary Appendix).

\section{PHARMACOKINETICS}

Pharmacokinetic analysis of PB2452 revealed dose-linear increases in mean exposure (maximum 


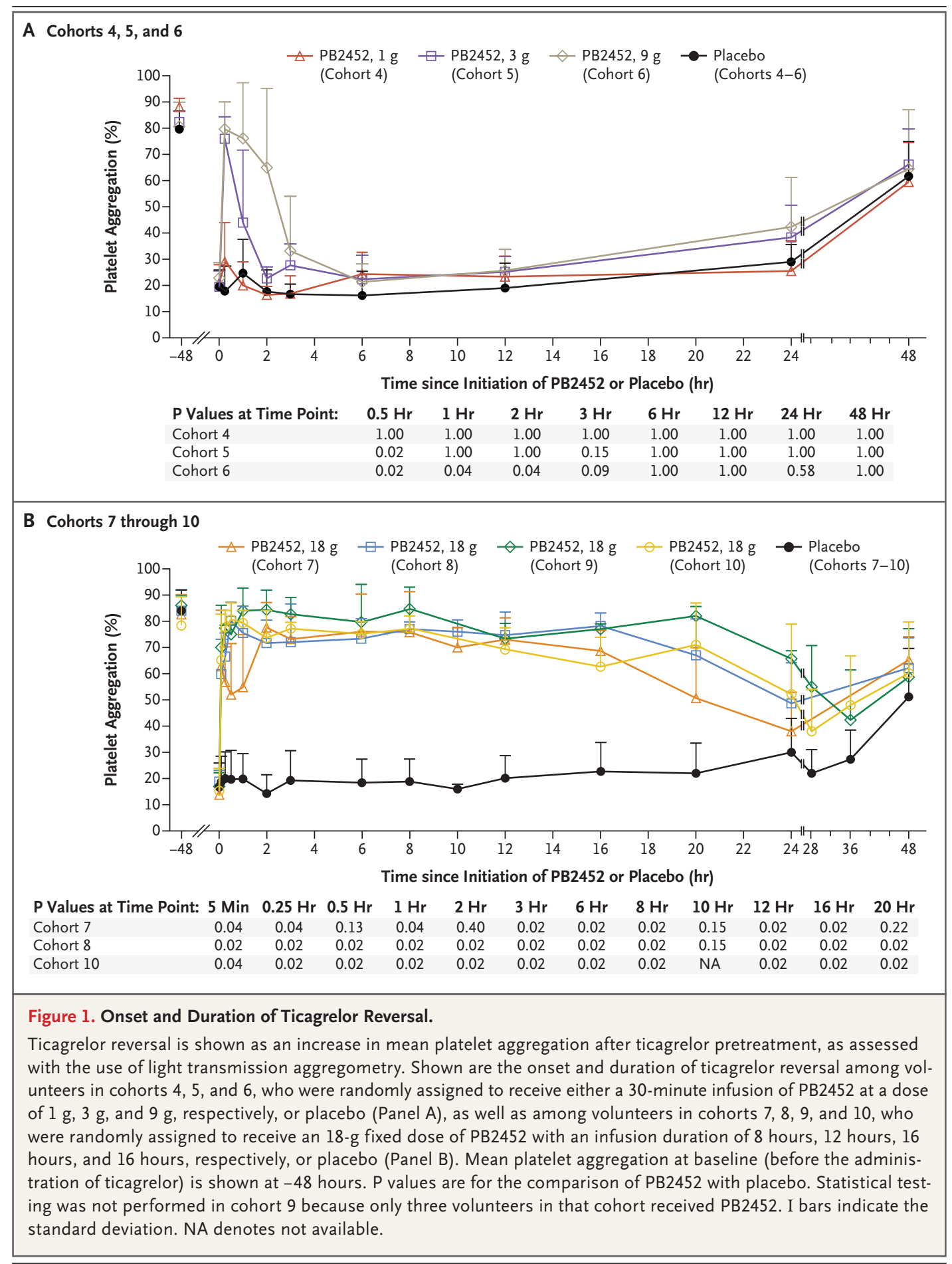

concentration and area under the curve from 0 to 48 hours $\left[\mathrm{AUC}_{0-48 \text { hours }}\right]$ ) across the dose range of 1.0 to $9.0 \mathrm{~g}$. Clearance was approximately $2.5 \mathrm{li}-$ ters per hour. The elimination half-life and volume of distribution varied across the dose range. Among volunteers who received placebo and ti- cagrelor pretreatment, the mean $\mathrm{AUC}_{0-48 \text { hours }}$ for ticagrelor ranged from 4730 to 6750 hours times nanograms per milliliter. Among volunteers who received 30-minute infusions of PB2452 and ticagrelor pretreatment, the mean $\mathrm{AUC}_{0-48 \text { hours }}$ for ticagrelor was increased by a factor of 2.0 to 5.6. 


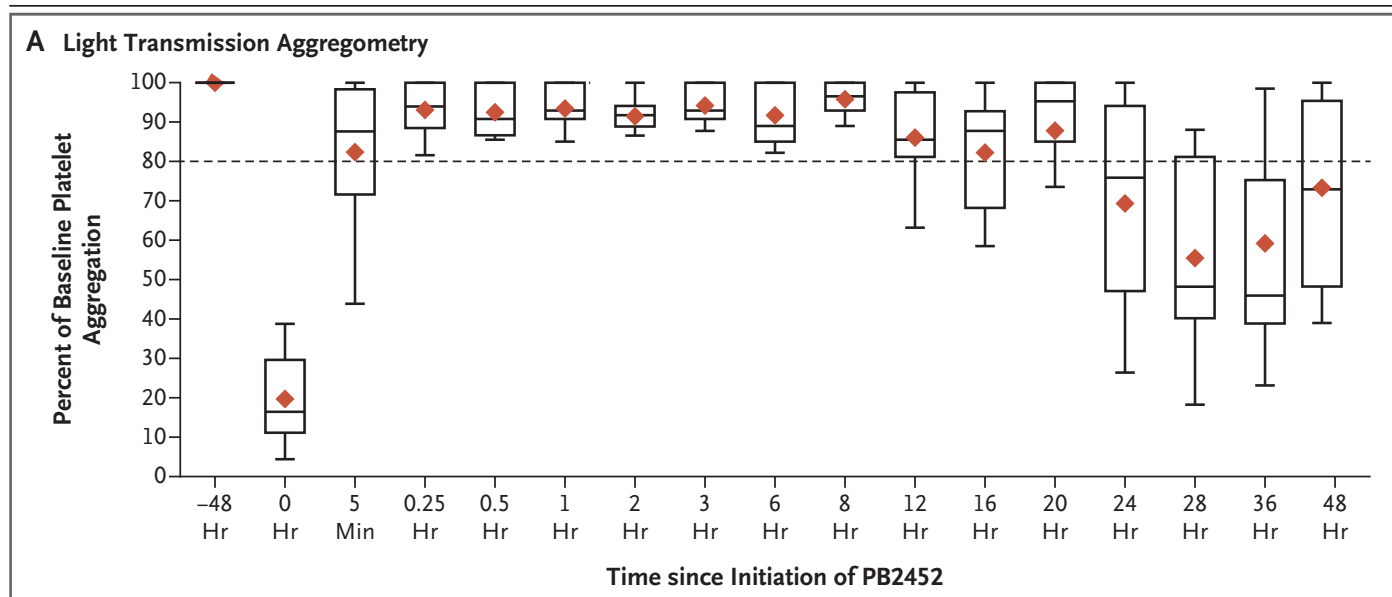

B Point-of-Care ${\mathrm{P} 2 \mathrm{Y}_{12}}_{12}$ Platelet-Reactivity Test

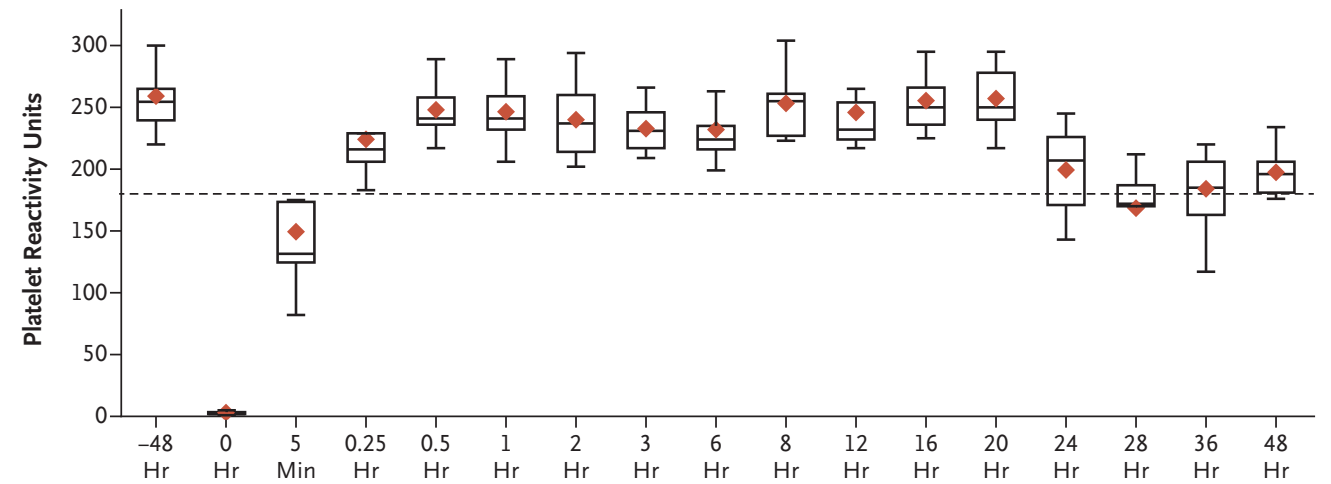

Time since Initiation of PB2452

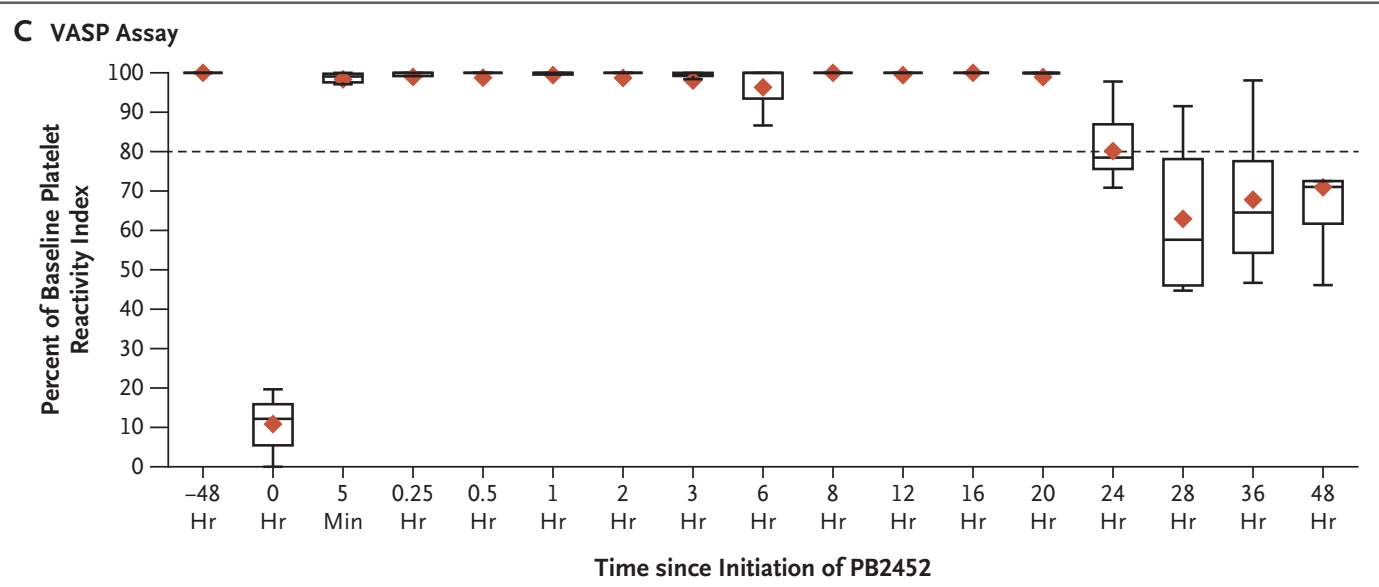

Figure 2. Normalization of Platelet Function after Ticagrelor Reversal.

Normalization of platelet function is shown as an increase in platelet function to within the normal range after ticagrelor pretreatment and subsequent initiation of PB2452. Shown are data from cohorts 9 and 10 (pooled). On light transmission aggregometry (Panel A), a normal level of platelet aggregation is at least $80 \%$ of the baseline value (dashed line). On the point-of-care $\mathrm{P}_{2} \mathrm{Y}_{12}$ platelet-reactivity test (Panel B), a normal level of platelet reactivity units is at least 180 (dashed line). On assessment of $\mathrm{P}_{2} \mathrm{Y}_{12}$ receptor signaling with the vasodilator-stimulated phosphoprotein (VASP) assay (Panel C), a normal platelet reactivity index is at least $80 \%$ of the baseline value (dashed line). Red diamonds indicate the mean, horizontal lines the median, and I bars the range. The tops and bottoms of the boxes indicate the third and first quartiles, respectively.

The New England Journal of Medicine 
Among volunteers who received $18 \mathrm{~g}$ of PB2452 with longer infusions and ticagrelor pretreatment, PB2452 exposure was maintained for 12 to 24 hours, and the mean $\mathrm{AUC}_{0-48 \text { hours }}$ for ticagrelor was increased by a factor of 5.6. The increased ticagrelor exposure probably reflected tight binding between PB2452 and ticagrelor and redistribution of extravascular ticagrelor into the vascular compartment. Details regarding the pharmacokinetic profiles of PB2452 and ticagrelor are provided in Figure S5A through S5D in the Supplementary Appendix.

\section{DISCUSSION}

In this trial, intravenous infusion of the monoclonal antibody fragment PB2452 significantly reversed the antiplatelet effects of ticagrelor, as measured by multiple assays of platelet function. In the healthy trial population, there were no serious adverse events or infusion-related reactions that were determined to be associated with PB2452. It remains unclear whether reversal of the antiplatelet effects of ticagrelor by PB2452 would lead to more rapid hemostasis in patients with bleeding or to prevention of bleeding in patients who are undergoing urgent invasive procedures.

The ability to reverse the action of novel oral anticoagulants has been a major advance in antithrombotic therapy. ${ }^{30,31}$ Currently, no effective methods for reversal of the antiplatelet effects of oral P2Y ${ }_{12}$ antagonists, such as ticagrelor, are available other than stopping the drug and waiting 3 to 5 days for its effects to dissipate, a method that is problematic in patients who have lifethreatening bleeding or a high risk of thrombosis. Treatment guidelines and prescription information for $\mathrm{P}_{2} \mathrm{Y}_{12}$ inhibitors recommend drug cessation 3 to 7 days before surgical procedures. Waiting this long is impossible in patients who are undergoing emergency surgery and may be inadvisable for those who are undergoing urgent surgery. Platelet transfusion may be considered for attempting reversal of aspirin and some $\mathrm{P}_{2} \mathrm{Y}_{12}$ receptor antagonists but is not useful in patients who are receiving ticagrelor, because the free drug binds to fresh platelets. ${ }^{32,33}$ Therefore, a ticagrelor reversal agent would be useful.

PB2452 is a recombinant human IgG1 monoclonal antibody antigen-binding fragment that binds with high affinity and specificity to rapidly neutralize ticagrelor and its active metabolite AR-C124910XX. ${ }^{28}$ The high affinity and specificity of PB2452 enables it to neutralize free ticagrelor and prevent binding to the $\mathrm{P}_{2} \mathrm{Y}_{12}$ receptor. These properties explain the immediate reversal that was observed with PB2452, and such reversal is a key feature for patients with hemorrhage. The mechanism of action is expected to be specific to ticagrelor and not work with clopidogrel or prasugrel, which are irreversible $\mathrm{P}_{2} \mathrm{Y}_{12}$ receptor antagonists.

There are some limitations of this trial. The trial involved healthy volunteers and not patients with atherosclerosis. The sample size was small. Because the trial involved healthy volunteers and not patients with bleeding who were already taking ticagrelor, the results may not be predictive of the reversal or safety profile of PB2452 in that patient population or the effect of PB2452 on the establishment of hemostasis or the prevention of bleeding.

Several clinical studies that have used the same assays have correlated platelet inhibition with bleeding risk. ${ }^{34-36}$ In a literature review and expert consensus statement and in a large meta-analysis of 17 clinical trials that included more than 20,000 patients who were undergoing percutaneous coronary intervention and whose platelet function was measured with the use of a point-of-care $\mathrm{P}_{2} \mathrm{Y}_{12}$ platelet-reactivity test or a VASP assay, low platelet reactivity was independently associated with an elevated bleeding risk. ${ }^{37,38}$ In this trial involving volunteers who were pretreated with ticagrelor, low platelet reactivity was rapidly reversed by a new targeted monoclonal antibody fragment.

In conclusion, we found that the administration of intravenous PB2452 reversed the antiplatelet effects of ticagrelor, as measured by multiple assays of platelet function, and was associated with minimal low-grade toxic effects.

\section{Supported by PhaseBio Pharmaceuticals.}

Disclosure forms provided by the authors are available with the full text of the article at NEJM.org.

A data sharing statement provided by the authors is available with the full text of this article at NEJM.org.

We thank the volunteers who participated in the trial, as well as LuAnn Bundrant, M.D., from Pharmaceutical Product Development, Janet Rush, M.D., and Covance Laboratories for assistance with medical monitoring, platelet-function analyses, and bioassay development, and Jayne Prats, Ph.D., for assistance with manuscript formatting and collation of coauthor comments for an earlier version of the manuscript (all funded by PhaseBio Pharmaceuticals). 


\section{REFERENCES}

1. Bhatt DL, Hulot JS, Moliterno DJ, Har rington RA. Antiplatelet and anticoagulation therapy for acute coronary syndromes. Circ Res 2014;114:1929-43.

2. Bhatt DL, Eagle KA, Ohman EM, et al Comparative determinants of 4-year cardiovascular event rates in stable outpatients at risk of or with atherothrombosis. JAMA 2010;304:1350-7.

3. The Clopidogrel in Unstable Angina to Prevent Recurrent Events Trial Investigators. Effects of clopidogrel in addition to aspirin in patients with acute coronary syndromes without ST-segment elevation. N Engl J Med 2001;345:494-502.

4. Mehta SR, Yusuf S, Peters RJ, et al. Effects of pretreatment with clopidogre and aspirin followed by long-term therapy in patients undergoing percutaneous coronary intervention: the PCI-CURE study. Lancet 2001;358:527-33.

5. Bhatt DL, Fox KA, Hacke W, et al. Clopidogrel and aspirin versus aspirin alone for the prevention of atherothrombotic events. N Engl J Med 2006;354:1706-17.

6. Bhatt DL, Flather MD, Hacke W, et al. Patients with prior myocardial infarction, stroke, or symptomatic peripheral arteria disease in the CHARISMA trial. J Am Coll Cardiol 2007;49:1982-8.

7. Chen ZM, Jiang LX, Chen YP, et al. Addition of clopidogrel to aspirin in 45,852 patients with acute myocardial infarction: randomised placebo-controlled trial. Lancet 2005;366:1607-21.

8. Wiviott SD, Braunwald E, McCabe $\mathrm{CH}$, et al. Prasugrel versus clopidogrel in patients with acute coronary syndromes. N Engl J Med 2007;357:2001-15.

9. Roe MT, Armstrong PW, Fox KAA, et al. Prasugrel versus clopidogrel for acute coronary syndromes without revascularization. N Engl J Med 2012;367:1297-309. 10. Wiviott SD, White HD, Ohman EM, et al. Prasugrel versus clopidogrel for patients with unstable angina or non-STsegment elevation myocardial infarction with or without angiography: a secondary, prespecified analysis of the TRILOGY ACS trial. Lancet 2013;382:605-13.

11. Smith SC Jr, Benjamin EJ, Bonow RO et al. AHA/ACCF secondary prevention and risk reduction therapy for patient with coronary and other atherosclerotic vascular disease: 2011 update: a guideline from the American Heart Association and American College of Cardiology Foundation. Circulation 2011;124:2458-73.

12. O'Gara PT, Kushner FG, Ascheim DD, et al. 2013 ACCF/AHA guideline for the management of ST-elevation myocardial infarction: a report of the American College of Cardiology Foundation/American Heart Association Task Force on Practice Guidelines. Circulation 2013;127(4):e362-e425.

13. Amsterdam EA, Wenger NK, Brindis RG, et al. 2014 AHA/ACC guideline for the management of patients with non-ST-ele- vation acute coronary syndromes: a report of the American College of Cardiology/ American Heart Association Task Force on Practice Guidelines. Circulation 2014; 130(25):e344-e426.

14. Wijns W, Kolh P, Danchin N, et al. Guidelines on myocardial revascularization. Eur Heart J 2010;31:2501-55.

15. Hamm CW, Bassand JP, Agewall S, et al. ESC guidelines for the management of acute coronary syndromes in patients presenting without persistent ST-segment elevation: the task force for the management of acute coronary syndromes (ACS) in patients presenting without persistent ST-segment elevation of the European Society of Cardiology (ESC). Eur Heart J 2011;32:2999-3054

16. Koski R, Kennedy B. Comparative review of oral P2Y $\mathrm{Y}_{12}$ inhibitors. P T 2018;43: 352-7.

17. Wallentin L, Becker RC, Budaj A, et al. Ticagrelor versus clopidogrel in patients with acute coronary syndromes. N Engl J Med 2009;361:1045-57.

18. Cannon CP, Harrington RA, James S, et al. Comparison of ticagrelor with clopidogrel in patients with a planned invasive strategy for acute coronary syndromes (PLATO): a randomised double-blind study. Lancet 2010;375:283-93.

19. James SK, Roe MT, Cannon CP, et al. Ticagrelor versus clopidogrel in patients with acute coronary syndromes intended for non-invasive management: substudy from prospective randomised PLATelet inhibition and patient Outcomes (PLATO) trial. BMJ 2011;342:d3527.

20. Plavix (clopidogrel bisulfate). Bridgewater, NJ: Bristol-Myers Squibb/Sanofi Pharmaceuticals, 2017 (package insert). 21. Brilinta (ticagrelor). Wilmington, DE: Astra Zeneca, 2016 (package insert).

22. Effient (prasugrel). Indianapolis: Eli Lilly, 2018 (package insert).

23. Bhatt DL. Prasugrel in clinical practice. N Engl J Med 2009;361:940-2.

24. Ducrocq G, Amarenco P, Labreuche J, et al. A history of stroke/transient ischemic attack indicates high risks of cardiovascular event and hemorrhagic stroke in patients with coronary artery disease. Circulation 2013;127:730-8.

25. Bhatt DL. Intensifying platelet inhibition - navigating between Scylla and Charybdis. N Engl J Med 2007;357:2078-81. 26. Hillis LD, Smith PK, Anderson JL, et al. 2011 ACCF/AHA guideline for coronary artery bypass graft surgery. a report of the American College of Cardiology Foundation/American Heart Association Task Force on Practice Guidelines: developed in collaboration with the American Association for Thoracic Surgery, Society of Cardiovascular Anesthesiologists, and Society of Thoracic Surgeons. J Am Coll Cardiol 2011;58(24):e123-e210.

27. Valgimigli M, Bueno H, Byrne RA, et al.
2017 ESC focused update on dual antiplatelet therapy in coronary artery disease developed in collaboration with EACTS: the task force for dual antiplatelet therapy in coronary artery disease of the European Society of Cardiology (ESC) and of the European Association for Cardio-Thoracic Surgery (EACTS). Eur Heart J 2018;39:213-60.

28. Buchanan A, Newton P, Pehrsson S, et al. Structural and functional characterization of a specific antidote for ticagrelor. Blood 2015;125:3484-90.

29. Gurbel PA, Bliden KP, Butler K, et al. Randomized double-blind assessment of the ONSET and OFFSET of the antiplatelet effects of ticagrelor versus clopidogrel in patients with stable coronary artery disease: the ONSET/OFFSET study. Circulation 2009;120:2577-85.

30. Pollack CV Jr, Reilly PA, Eikelboom J, et al. Idarucizumab for dabigatran reversal. N Engl J Med 2015;373:511-20.

31. Siegal DM, Curnutte JT, Connolly SJ, et al. Andexanet alfa for the reversal of factor Xa inhibitor activity. N Engl J Med 2015;373:2413-24.

32. Godier A, Taylor G, Gaussem P. Inefficacy of platelet transfusion to reverse ticagrelor. N Engl J Med 2015;372:196-7.

33. Teng R, Carlson GF, Nylander S, Andersson TL. Effects of autologous platelet transfusion on platelet inhibition in ticagrelor-treated and clopidogrel-treated subjects. J Thromb Haemost 2016;14:2342-52.

34. Jin L, Yu H, Dong T, et al. The prognostic value of ADP-induced platelet aggregation for bleeding complications in low-intermediate risk patients with acute coronary syndrome taking clopidogrel after percutaneous coronary intervention. Heart Lung Circ 2017;26:49-57.

35. Reed GW, Kumar A, Guo J, et al. Point-of-care platelet function testing predicts bleeding in patients exposed to clopidogrel undergoing coronary artery bypass grafting: verify pre-op TIMI $45-$ a pilot study. Clin Cardiol 2015;38:92-8.

36. Mangiacapra F, Ricottini E, Barbato $\mathrm{E}$, et al. Incremental value of platelet reactivity over a risk score of clinical and procedural variables in predicting bleeding after percutaneous coronary intervention via the femoral approach: development and validation of a new bleeding risk score. Circ Cardiovasc Interv 2015;8(5):e002106. 37. Tantry US, Bonello L, Aradi D, et al. Consensus and update on the definition of on-treatment platelet reactivity to adenosine diphosphate associated with ischemia and bleeding. J Am Coll Cardiol 2013;62:2261-73.

38. Aradi D, Kirtane A, Bonello L, et al. Bleeding and stent thrombosis on $\mathrm{P}_{2} \mathrm{Y}_{12}$ inhibitors: collaborative analysis on the role of platelet reactivity for risk stratification after percutaneous coronary intervention. Eur Heart J 2015;36:1762-71.

Copyright (c) 2019 Massachusetts Medical Society. 